WellBeing International

WBI Studies Repository

$9-5-2003$

\title{
The Evidence for Pain in Fish: The Use of Morphine as an Analgesic
}

Lynne U. Sneddon

Roslin Institute

Follow this and additional works at: https://www.wellbeingintlstudiesrepository.org/acwp_vsm

Part of the Animal Studies Commons, Other Animal Sciences Commons, and the Veterinary Toxicology and Pharmacology Commons

\section{Recommended Citation}

Sneddon, L. U. (2003). The evidence for pain in fish: the use of morphine as an analgesic. Applied Animal Behaviour Science, 83(2), 153-162.

This material is brought to you for free and open access by WellBeing International. It has been accepted for inclusion by an authorized administrator of the WBI Studies Repository. For more information, please contact wbisr-info@wellbeingintl.org.

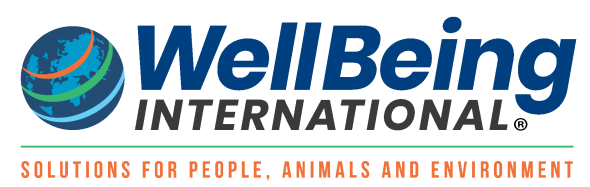




\title{
The Evidence for Pain in Fish: The Use of Morphine as an Analgesic
}

\author{
Lynne U. Sneddon \\ Roslin Institute
}

\section{KEYWORDS}

pain, nociception, fish, rainbow trout, morphine

\begin{abstract}
This paper discusses the evidence for pain perception in fish and presents new data on morphine analgesia in fish. Recent anatomical and electrophysiological studies have demonstrated that fish are capable of nociception, the simple detection of a noxious, potentially painful stimulus and the reflex response to this. To prove pain perception, it must be demonstrated that an animal's behaviour is adversely affected by a potentially painful event and this must not be a reflex response. The present study examined the acute effects of administering a noxious chemical to the lips of rainbow trout (Oncorhynchus mykiss) to assess what changes occurred in behaviour and physiology. There was no difference in swimming activity or use of cover when comparing the noxiously stimulated individuals with the controls. The noxiously treated individuals performed anomalous behaviours where they rocked on either pectoral fin from side to side and they also rubbed their lips into the gravel and against the sides of the tank. Opercular beat rate (gill or ventilation rate) increased almost double fold after the noxious treatment whereas the controls only showed a 30\% increase. Administering morphine significantly reduced the pain-related behaviours and opercular beat rate and thus morphine appears to act as an analgesic in the rainbow trout. It is concluded that these pain-related behaviours are not simple reflexes and therefore there is the potential for pain perception in fish.
\end{abstract}

\section{Introduction}

The question of pain perception in fish is a controversial one with two opposing views. Many angling groups suggest that fish are incapable of pain perception (LeChat, 1996; Rose, 2002 although see De Leeuw, 1996; Balon, 2000) and some scientific papers support this view (Leonard, 1985; Macphail, 1998; Snow et al., 1993; Rose, 2002). However there is evidence that fish are as capable as many other animals of pain perception (Beukema, 1970a, b; Ehrensing et al., 1982; Verheijen and Flight, 1997; 
Gregory, 1999). Studies on three species of elasmobranchs failed to identify nociceptors and concluded that fish do not have the neural apparatus to detect pain (Leonard, 1985; Snow et al., 1993; Rose, 2002) although in other studies nociceptors were found (Sneddon, 2002, 2003; Sneddon et al., 2003). In a review concluding that fish are not capable of pain perception, Rose (2002) defined pain in terms of brain structure and stated that an animal must have the necessary brain structure, a neocortex, to perceive pain. With this definition only humans and primates are capable of experiencing pain and Rose (2002) conveniently ignored the bird and amphibian literature that has proven these animals are capable of pain and yet they do not have a neocortex (Gentle, 1992; Stevens, 1992). Recent experimental evidence of possible pain perception in fish has come to light (Sneddon, 2002; Sneddon and Gentle, 2002). These studies demonstrated the presence of nociceptors using techniques in neuroanatomy and electrophysiology (Sneddon, 2002; Sneddon and Gentle, 2002). Nociceptors are receptors that preferentially detect noxious, damaging stimuli and have been characterised in a wide variety of animals and in humans (Lynn, 1994). The rainbow trout nociceptors were found on the head of the fish and around the lips and gill cover (Sneddon and Gentle, 2002; Sneddon et al., 2003) and these nociceptors had identical properties to those found in mammals (Sneddon, 2003). Therefore, it is vital that we assess whether this fish is capable of pain perception.

The commonly used definition of pain has been proposed by Zimmerman (1986) and states that pain in animals is an adverse sensory experience that is caused by a stimulus that can or potentially could cause tissue damage; this experience should elicit protective motor (move away from stimulus) and vegetative reactions (e.g. inflammation and cardiovascular responses) and should also have an adverse effect on the animal's general behaviour (e.g. cessation of normal behaviours). So being more than a sensory experience, pain has to be associated with a "feeling" or negative perception (Broom, 2000). These guidelines have been adopted by many researchers (Broom, 1991; Bateson, 1992; Gentle, 1992, 2001; Molony et al., 2002). It has already been demonstrated that fish can learn to avoid noxious events such as electric shock (e.g. goldfish, Ehrensing et al., 1982; Davis and Klinger, 1994) and hooking during angling (e.g. carp and pike, Beukema, 1970a, b) and it also been shown that behaviour is disrupted after angling whereby smallmouth bass do not return to their nesting site when released back into the water (Kieffer et al., 1995). Along with the anatomical and neurophysiological confirmation of nociceptive capabilities in the rainbow trout (Sneddon, 2002; Sneddon and Gentle, 2002), this behavioural evidence suggests that there is the possibility of pain perception in fish.

The present study aimed to assess the acute effects of noxious stimulation on the behavior and ventilation rate of the rainbow trout, Oncorynchus mykiss, to assess if a potentially painful event adversely affected behavioural and physiological output. Morphine was administered to another noxiously stimulated group to determine if any behavioural and physiological responses can be ameliorated by an analgesic and this could potentially provide significant evidence of pain in a fish.

\section{Materials and methods}

\subsection{Animals}

Twenty-five rainbow trout (mean weight $61 \mathrm{~g} \pm 5 \mathrm{~g}$ ) were obtained from a commercial fish supplier. Individual fish were housed in rectangular tanks $(45 \mathrm{~cm} \times 25 \mathrm{~cm} \times 35 \mathrm{~cm})$ with a constant flow of filtered freshwater at $11{ }^{\circ} \mathrm{C} \pm 1{ }^{\circ} \mathrm{C}$. One-half of the tank was covered by an opaque lid $(22.5 \mathrm{~cm} \times 25 \mathrm{~cm})$ to provide an area of shelter, whereas, the other half had a transparent lid to provide an open area. A white feeding ring (10 cm diameter) was secured to the side of the tank in the open area on the water surface. Each tank had a gravel substrate and was continuously aerated via an airstone and tubing connected to an air pump (Mistral Series 4; Interpet, UK). A Series 1 internal filter (Interpet, UK) was also present in each tank to remove debris and uneaten food. 


\subsection{Treatments}

Each fish was trained twice daily, AM and PM, to respond to a light cue above the tank by coming to the feeding ring to receive food pellets (TROUW Aquaculture, UK; mean number of trials to learn $=10 \pm 4$ ). Once the fish had learned to feed at the ring they received 1 week's further training to ensure that they were fully conditioned to the light stimulus. Fish were then assigned to four treatment groups.

\subsubsection{Saline}

In this treatment, $0.1 \mathrm{ml}$ sterile saline was injected ( $25 \mathrm{~g}$ needle and $1 \mathrm{ml}$ syringe) into frontal lips.

\subsubsection{Acid}

In this treatment, $0.1 \mathrm{ml}$ acetic acid ( $0.1 \%$ in sterile saline) was injected into lips.

\subsubsection{Acid-Morphine}

In this treatment, $0.1 \mathrm{ml}$ acetic acid injected into lips and morphine sulfate $(0.3 \mathrm{~g} / 1 \mathrm{ml}$ sterile saline) was injected intramuscularly $(0.1 \mathrm{ml} / 10 \mathrm{~g}$ fish weight).

\subsubsection{Control}

In this treatment, fish were handled but received no injection.

\subsubsection{Morphine}

In this treatment, fish were handled with no injection and morphine administered. Acetic acid was chosen since the protons of the acid stimulate nociceptive nerves and this is a standard pain test in animals, including humans (Martinez et al., 1999; Hamamoto et al., 2000; Sneddon, 2002). Before treatment the behaviour and opercular (gill) beat rate were recorded continuously for $15 \mathrm{~min}$. Behaviours measured were use of cover and frequency of swimming activity (direct movement of fish more than one body length). Fish were then individually anaesthetised using benzocaine $(1.5 \mathrm{ml}(50 \mathrm{mg} / \mathrm{l}$ of ethanol $) / \mathrm{l})$ and were carefully injected with the appropriate substance into the upper and lower frontal lip or handled but not injected. The fish were in medium to deep plane anaesthesia during this procedure and had lost all reflex activity and muscular control. The fish were placed back into their original tank allowing 30 min to recover from the anaesthesia and handling. After this $30 \mathrm{~min}$ period, behaviour and opercular beat rate were recorded for $15 \mathrm{~min}$ and then the light switched on and food introduced to the tank. If the fish did not feed they were left for a further $30 \mathrm{~min}$, then another $15 \mathrm{~min}$ of observations were recorded and tested for performance of the conditioned task. This regime continued until the fish actually ingested food. All fish resumed eating food within $4 \mathrm{~h}$.

\subsection{Statistics}

The time to resume feeding for the four groups was compared using one-way ANOVA. The percentage of time spent in the covered area for each fish in all five groups was determined before and after the treatment and compared using Mann-Whitney $U$-tests. Frequency of swimming activity was calculated for each fish in the experimental groups and before and after the treatment, which was compared using Mann-Whitney $U$-tests. Differences in cover use and swimming activity between the test groups were analysed using Kruskall-Wallis tests. Opercular beat rate was compared between the five groups after treatment using one-way ANOVA and before and after effects were compared using paired $T$-tests. 
Fig. 1. (A) Mean time (+S.E.) taken for the treatment groups to begin ingesting food ( $n=5$ per group). There was a significant difference in the time taken to resume feeding between the groups $\left(F_{4,20}=7.29, P=0.003\right)$. (B) Mean (+S.E.) frequency of swimming performed for all of the treatment groups. There was no difference between the groups in the amount of swimming they performed after the treatment $(H=4.94, \mathrm{df}=4, P=0.085)$. (C) The mean (+S.E.) proportion of time that the treatment groups spent under cover. There was no difference in cover use between the experimental groups after the treatment $(H=1.15$, df $=4, P=0.765)$.

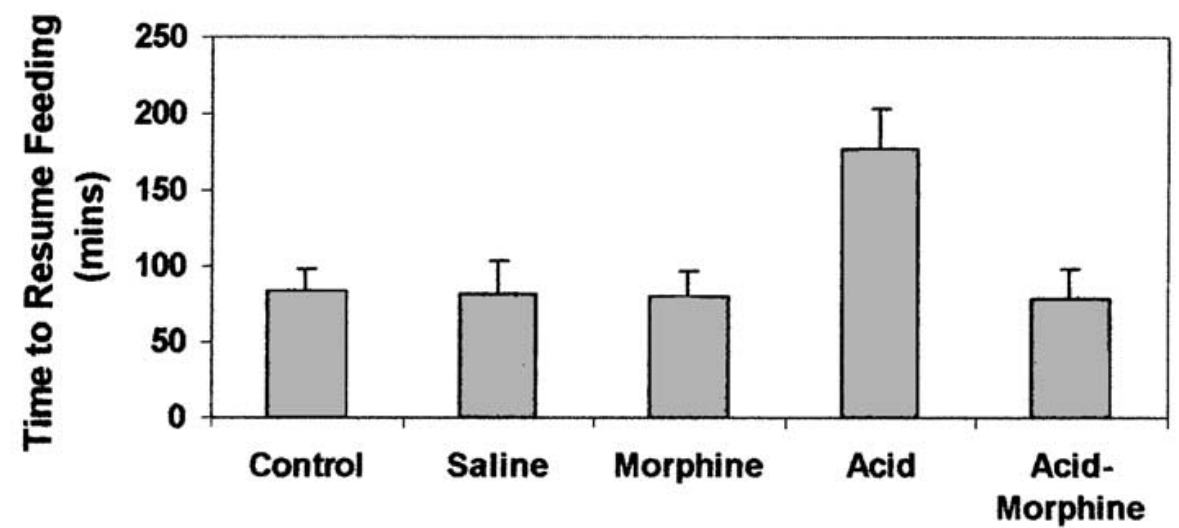

(A)

\section{Group}

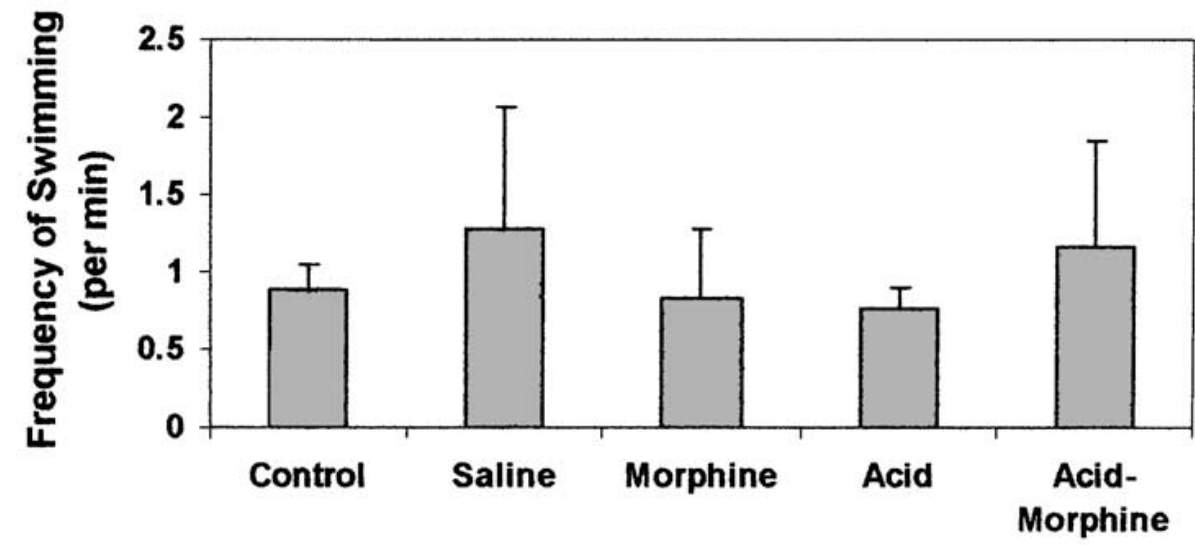

(B)

\section{Group}

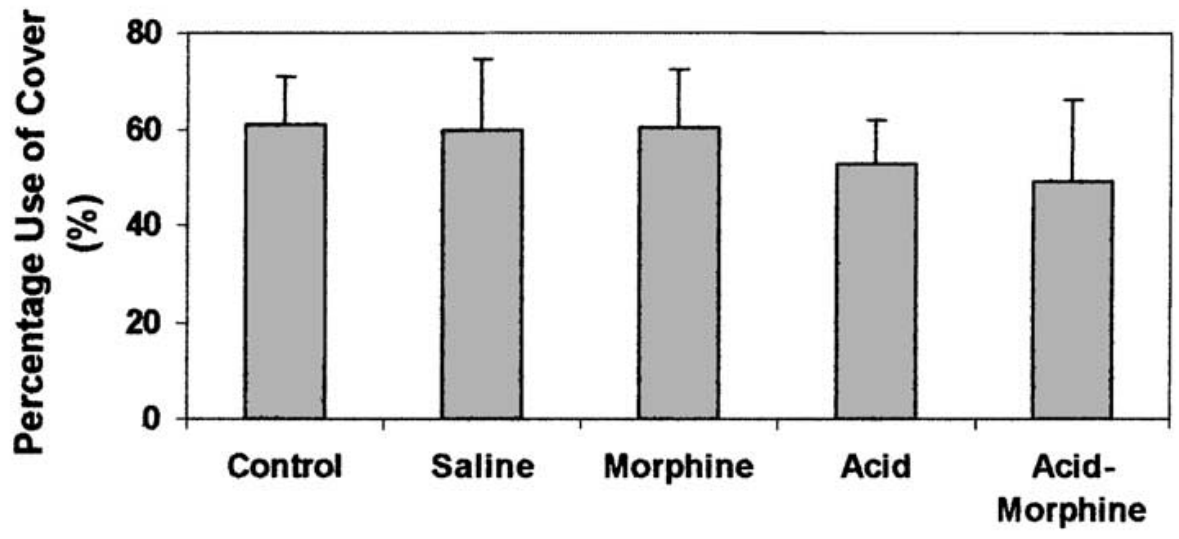

(C)

Group 
Fig. 2. (A) Mean (+S.E.) frequency of rocking behaviour after acid injection in the Acid and Acid-Morphine groups. There was a significant reduction in rocking when morphine was administered $(H=3.84, \mathrm{df}=1, P=0.05 ; n=5$ per group). (B) Mean (+S.E.) frequency of rubbing performed by the Acid and Acid-Morphine groups. There was significantly less rubbing performed after morphine administration $(H=6.86, \mathrm{df}=1, P=0.01)$.

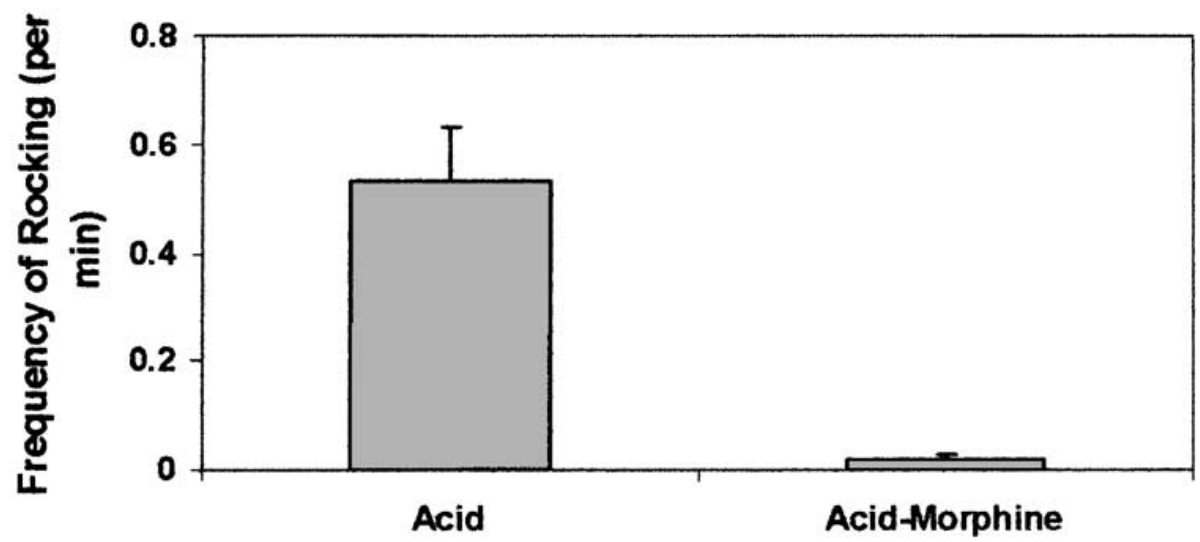

(A)

Group

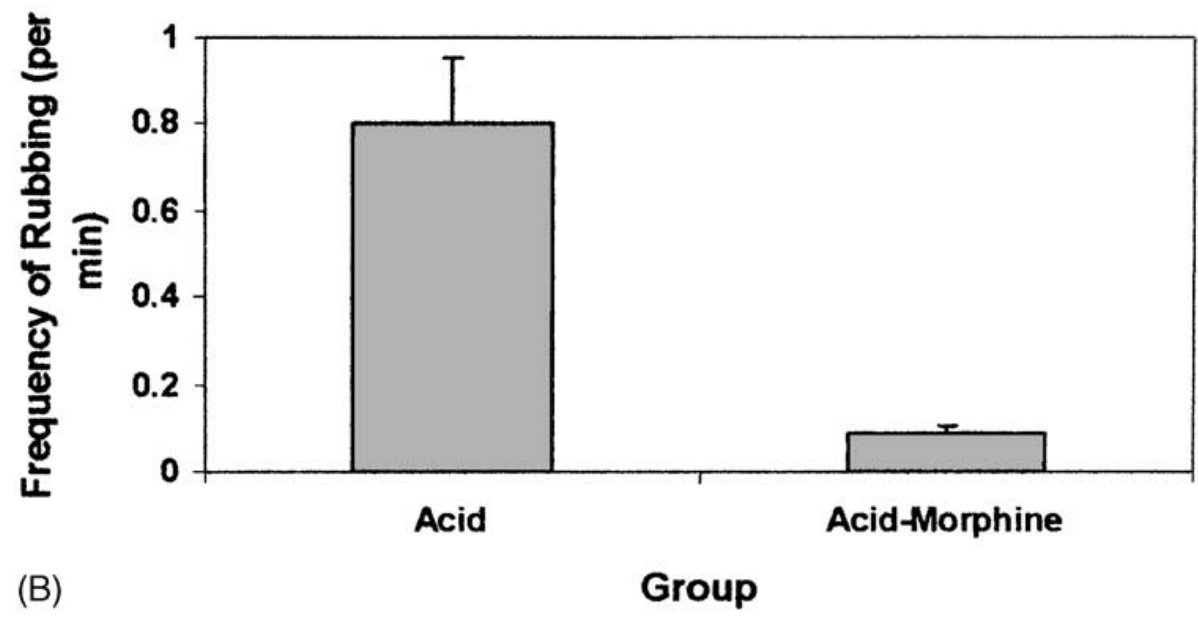

\section{Results}

It took Control, Saline, Acid-Morphine and Morphine fish approximately $80 \mathrm{~min}$ to begin ingesting food again whereas Acid fish took approximately $170 \mathrm{~min}$ (Fig. $1 \mathrm{~A}, F_{4,20}=7.29, P=0.003$ ). There was no difference in the amount of swimming performed by the five different treatment groups $(H=4.94, \mathrm{df}=4, P$ $=0.085$; Fig. 1B). There was no change in the frequency of swimming activity after the treatment in the Control $(W=27.5, n=5, P=1.0)$; Saline $(W=29, n=5, P=0.83)$; Morphine $(W=30, n=5, P=0.75)$ Acid $(W=29, n=5, P=0.83)$; and Acid-Morphine groups ( $W=26, n=5, P=0.83)$. Use of cover was also not affected by the noxious injection (Acid, $W=29, n=5, P=0.83$; Acid-Morphine, $W=26, n=5, P$ $=0.83$ ) or the controls treatments (Control, $W=25 ; P=0.75$; Saline, $W=32, n=5, P=0.46$; Morphine, $W=26, n=5, P=0.83)$ and there was no difference in use of cover between the five treatment groups $(H$ $=1.15, \mathrm{df}=4, P=0.765$; Fig. 1C).

Anomalous behaviours were performed by the Acid and Acid-Morphine groups after the treatment and these were not seen in the Control, Saline or Morphine groups; Acid and Morphine fish performed "rocking" where the fish moved from side to side on either pectoral fin whilst resting on the gravel (mean 
frequency $0.53 / \mathrm{min}$ for the Acid group; 0.02/min for the Acid-Morphine group; Fig. 2A). The Acid and Acid-Morphine groups also rubbed their lips into the gravel and against the tank walls (mean frequency 0.80/min for the Acid group; 0.09/min for the Morphine group; Fig. 2B). There was a significant reduction in rocking $(H=3.84, \mathrm{df}=1, P=0.05)$ and rubbing $(H=6.86$, df $=1, P=0.01)$ in Acid-Morphine treated animals as compared with Acid animals.

These behavioural effects of acid injection were accompanied by a profound effect on the fish's physiology. Significant increases in opercular beat rate were found in the Acid group (approximately 52 beats/min before to 93 beats/min after treatment, Fig. 3) that were not seen in the Control, Saline, Morphine or Acid-Morphine groups (52 beats $/ \mathrm{min}$ to 67 beats $/ \mathrm{min}$ after treatment; $F_{4,20}=27.52$, $P<0.001$; Fig. 3). All treatment groups showed a significant rise in opercular beat rate after the treatment (Control, $T=-9.2, P<0.001$, df = 7; Saline, $T=-21.5, P<0.001$, df = 7; Morphine, $T=-11.6, P<0.001$, $\mathrm{df}=7$; Acid, $T=-27.7, P<0.001, \mathrm{df}=7$; Acid-Morphine, $T=-7.6, P<0.001, \mathrm{df}=7$ ).

Fig. 3. The mean (+S.E.) opercular beat rate after the treatment in the five experimental groups ( $n=5$ per group). The Acid group had a significantly higher opercular beat rate than the other four treatment groups $(F 4,20=27.52, P<$ $0.001)$.

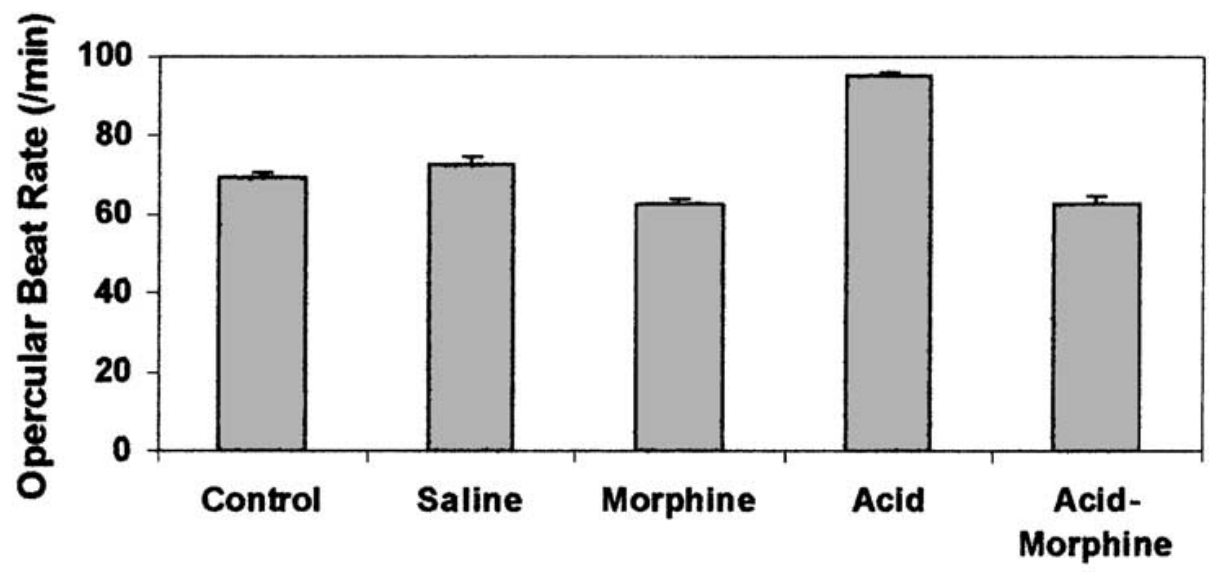

Group

\section{Discussion}

The study demonstrated that there were adverse behavioural and physiological consequences in the rainbow trout in response to a noxious, potentially painful event. After injection of an algogenic substance, fish performed anomalous behaviours that were not performed by the Control groups. Rocking behaviour was seen in both Acid and Acid-Morphine treatment groups. This may be similar to the stereotypical rocking behaviour of primates and zoo animals that is believed to be an indicator of poor welfare and thought to be a comfort behaviour (Gonyou, 1994). The acid injected fish also rubbed their lips against the gravel and the sides of the tank. The act of rubbing an injured area to ameliorate the intensity of pain has been observed in humans and in mammals (e.g. Rattus rattus, Roveroni et al., 2001). The performance of anomalous behaviours usually occurs within a short time period after the occurrence of a painful event when the pain is most intense (Molony et al., 2002) and these rocking and rubbing behaviours were only observed in the 1.5 hours after acid injection. These behaviours have not been recorded in fish before and these may be pain-coping strategies that may have a potential use as indicators of pain or the occurrence of a noxious event in fish. Pain may be species specific and 
behavioural changes have been shown to be specific to different types of pain and thus, each different form of pain may have different behavioural responses (Kavaliers, 1988). Therefore, further studies should investigate the response of different fish species to establish whether the behaviours seen in this study are universal in fish.

The Acid group individuals took much longer to begin ingesting food (approximately 180 min) than the Saline, Control, Acid-Morphine and Morphine groups (approximately $80 \mathrm{~min}$ ). Guarding a painful limb or area by not using it to prevent more pain and damage being caused is common in animals (Gentle, 1992) and this may explain why the Acid group took longer to resume feeding. It appears as if the rainbow trout does not feed when affected by the administration of a noxious agent to the lips and only resumes feeding when the behavioural and physiological effects subside.

The increase in opercular beat rate in the Acid group is similar to that recorded when rainbow trout are swimming at maximum speed (Altimiras and Larsen, 2000) and much greater than the rate recorded for the other treatment groups, which is similar to rate recorded in salmonids after handling stress (increase to a maximum of 69 beats/min; Laitinen and Valtonen, 1994). The handling and anaesthetic procedure would be stressful and so this accounts for the rise in the Control, Saline, Morphine and Acid-Morphine groups. This dramatic rise in ventilation rate in the Acid groups is similar to respiratory changes in mammals and humans enduring a nociceptive event (Kato et al., 2001) and so the profound increase in ventilation rate may be a physiological response to noxious, painful stimulation in the rainbow trout.

Morphine had a significant effect on the fish in this study and acted as an analgesic or antinociceptive. The administration of morphine had a dramatic effect on pain-related behaviours and opercular beat rate by reducing them substantially and the changes in opercular beat rate was similar to the control groups. The Acid-Morphine fish did still perform a very small frequency of rubbing and rocking so perhaps the morphine dose could have been increased to cause a complete cessation of these behaviours. The analgesic effects of morphine are well known in animals and humans (Plomb et al., 1980; Kavaliers and Innes, 1992; Ebersberger et al., 1995) however, no work has been previously done on analgesia in fish. Fish can become tolerant of morphine and have opioid receptors (Jensen and Green, 1970) and morphine does impair electric shock aversion training in goldfish (Carassius auratus, Ehrensing et al., 1982).

\section{Conclusion}

The behaviours shown by the trout after injection of a noxious stimulus are complex in nature and this suggests higher processing is involved. These behavioural and physiological responses are reduced by morphine analgesia. The performance of a stereotypical or comfort behaviour and rubbing of the affected area are not simple reflexes and these behavioural changes are similar to some of the pain-related responses of higher vertebrates (Gonyou, 1994; Roughan and Flecknell, 2001) and man (Kato et al., 2001) to noxious stimuli. Therefore, it is likely that fish are capable of pain perception and this study has shown that the criteria for animal pain have been fulfilled (Zimmerman, 1986) hence it appears that fish can perceive pain. From an ethical point of view, these results are relevant to the use and treatment of fish in commercial fish production, angling and scientific experimentation.

\section{Acknowledgements}

I am grateful to BBSRC for financial support (Grant no. 215/S11042); to Mike Gentle (Roslin Institute) and Victoria Braithwaite (Edinburgh University) for the use of their laboratory facilities; and to Anthea Springbett (Roslin Institute) for her advice on the statistics. 


\section{References}

Altimiras, J., Larsen, E.J., 2000. Non-invasive recording of heart rate and ventilation rate in rainbow trout during rest and swimming: fish go wireless. J. Fish Biol. 57, 197-209.

Balon, E.K., 2000. Defending fishes against recreational fishing: an old problem to be solved in the new millennium. Environ. Biol. Fishes 57, 1-8.

Bateson, P., 1992. Assessment of pain in animals. Anim. Behav. 42, 827-839.

Beukema, J.J., 1970a. Angling experiments with carp (Cyprinus carpio L.). Part II. Decreased catchability through one trial learning. Neth. J. Zool. 19, 81-92.

Beukema, J.J., 1970b. Acquired hook avoidance in the pike Esox lucius L. fished with artificial and natural baits. J. Fish Biol. 2, 155-160.

Broom, D.M., 1991. Animal welfare: concepts and measurements. J. Anim. Sci. 69, 4167-4175.

Broom, D.M., 2000. Evolution of pain. In: Soulsby, L., Morton, D. (Eds.), Proceedings of the Royal Society of Medical International Congress Symposium Series on In Pain: Its Nature and Management in Man and Animals, vol. 246, pp. 17-25.

Davis, R.E., Klinger, P.D., 1994. NMDA receptor antagonist MK-801 blocks learning of conditioned stimulus-unconditioned stimulus contiguity but not fear of conditioned stimulus in goldfish (Carassius auratus). Behav. Neurosci. 108, 935-940.

De Leeuw, A.D., 1996. Contemplating the interests of fish: the angler's challenge. Environ. Ethics 18, 373-390.

Ebersberger, A., Anton, F.,Tolle,T.R., Zieglgansberger,W., 1995. Morphine 5-HT2 and 5-HT3 receptor antagonists reduce $\mathrm{C}$-fos expression in the trigeminal nuclear-complex following noxious chemical-stimulation of the rat nasal-mucosa. Brain Res. 676, 336-342.

Ehrensing, R.H., Michell, G.F., Kastin, A.J., 1982. Similar antagonism of morphine analgesia by MIF-1 and naxolone in Carassius auratus. Pharm. Biochem. Behav. 17, 757-761.

Gentle, M.J., 1992. Pain in birds. Anim. Welfare 1, 235-247.

Gentle, M.J., 2001. Attentional shifts alter pain perception in the chicken. Anim. Welfare 10, S187-194.

Gonyou, H.W., 1994. Why the study of animal behaviour is associated with the animal welfare issue. J. Anim. Sci. 72, 2171-2177.

Gregory, N., 1999. Do fish feel pain? ANZCCART News 12, 1-3.

Hamamoto, D.T., Forkey,M.W., Davis,W.L., Kajander, K.C., Simone, D.A., 2000. The role of pH and osmolarity in evoking the acetic acid-induced wiping response in a model of nociception in frogs. Brain Res. 862, 217-229.

Jensen, G.A., Green, N.M., 1970. Morphine metabolism and morphine tolerance in goldfish. Anesthesiology 32, 231-235. 
Kato,Y.,Kowalski, C.J., Stohler, C.S., 2001. Habituation of the early pain-specific respiratory response in sustained pain. Pain 91, 57-63.

Kavaliers, M., 1988. Evolutionary and comparative aspects of nociception. Brain Res. Bull. 21, 923-931.

Kavaliers, M., Innes, D.G.L., 1992. Sex differences in the effects of Tyr-MIF-1 on morphine- and stressinduced analgesia. Peptides 13, 1295-1297.

Kieffer, J.D., Kubacki, M.R., Phelan, F.J.S., Philipp, D.P., Tufts, B.L., 1995. Effects of catch-and-release angling on nesting male smallmouth bass. Trans. Am. Fish. Soc. 124, 70-76.

Laitinen, M., Valtonen, T., 1994. Cardiovascular, ventilatory and total activity responses of brown trout to handling stress. J. Fish Biol. 45, 933-942.

LeChat, M.R., 1996. An argument in defense of fishing. Fisheries 21, 20-21.

Leonard, R.B., 1985. Primary afferent receptive field properties and neurotransmitter candidates in a vertebrate lacking unmyelinated fibres. Prog. Clin. Biol. Res. 176, 135-145.

Lynn, B., 1994. The fibre composition of cutaneous nerves and the classification and response properties of cutaneous afferents, with particular reference to nociception. Pain Rev. 1, 172-183.

Macphail, E.M., 1998. The Evolution of Consciousness. Oxford University Press, New York.

Martinez, V., Thakur, S., Mogil, J.S., Tache, Y.,Mayer, E.A., 1999. Differential effects of chemical and mechanical colonic irritation on behavioural pain response to intraperitoneal acetic acid in mice. Pain 81, 179-186.

Molony, V., Kent, J.E., McKendrick, I.J., 2002. Validation of a method for assessment of acute pain in lambs. Appl. Anim. Behav. Sci. 76, 215-238.

Plomb, G.J.J., Maes, R.A.A., van Ree, J.M., 1980. Disposition of morphine in rat brain: relationship to biological activity. J. Pharmacol. Exp. Ther. 217, 181-188.

Rose, J.D., 2002. The neurobehavioral nature of fishes and the question of awareness and pain. Fisheries Sci. 10, 1-38.

Roughan, J.V., Flecknell, P.A., 2001. Behavioural effects of laparotomy and analgesic effects of ketoprofen and carprofen in rats. Pain 90, 65-74.

Roveroni, R.C., Parada, C.A., Cecilia, M., Veiga, F.A., Tambeli, C.H., 2001. Development of a behavioural model of TMJ pain in rats: the TMJ formalin test. Pain 94, 185-191.

Sneddon, L.U., 2002. Anatomical and electrophysiological analysis of the trigeminal nerve in the rainbow trout, Oncorhynchus mykiss. Neurosci. Lett. 319, 167-171.

Sneddon, L.U., 2003. Trigeminal somatosensory innervation of the head of the teleost fish with particular reference to nociception. Brain Res. 972, 44-52.

Sneddon, L.U., Braithwaite, V.A., Gentle, M.J., 2003. Do fish have nociceptors: evidence for the evolution of a vertebrate sensory system. Proc. Roy. Soc. Lond. B 270, 1115-1121. 
Sneddon, L.U., Gentle, M.J., 2002. Receptor types on the head of the rainbow trout: are nociceptors present? Comp. Biochem. Physiol. 32A (Suppl. 1), S42.

Snow, P.J., Plenderleith, M.B., Wright, L.L., 1993. Quantitative study of primary sensory neurone populations of three species of elasmobranch fish. J. Comp. Neurol. 334, 97-103.

Stevens, C.W., 1992. Alternatives to the use of mammals for pain research. Life Sci. 50, 901-912.

Verheijen, F.J., Flight,W.F.G., 1997. Decapitation and brining: experimental tests showthat after these commercial methods for slaughtering eel Anguilla anguilla (L.), death is not instantaneous. Aquacult. Res. 28, 361-366.

Zimmerman, M., 1986. Physiological mechanisms of pain and its treatment. Klinische Anäesthesiol. Intensivtherapie 32, 1-19. 